\title{
ARTICLE
}

The double burden of 'malnutrition': Under-Nutrition \& Obesity

\section{Stunting in infancy, pubertal trajectories and adult body composition: the Birth to Twenty Plus cohort, South Africa}

\author{
Glory Chidumwa ${ }^{1}$ Rihlat Said-Mohamed $\mathbb{C}^{1,2}$ - Lukhanyo H. Nyati ${ }^{1}$. Feziwe Mpondo ${ }^{1} \cdot$ Tinashe Chikowore $^{1}$. \\ Alessandra Prioreschi $^{1}$ - Juliana Kagura ${ }^{1,3} \cdot$ Lisa J. Ware ${ }^{1} \cdot$ Lisa K. Micklesfield $^{1}$ - Shane A. Norris ${ }^{1,4}$
}

Received: 9 March 2020 / Revised: 19 June 2020 / Accepted: 4 August 2020 / Published online: 14 August 2020

(c) The Author(s) 2020. This article is published with open access

\begin{abstract}
Background/objectives Childhood rapid growth and earlier puberty onset have been associated with adult obesity. However, the association between childhood stunting, pubertal timing and adult obesity is unclear. We examined whether the relationship between stunting at age 2 years (y) and body composition at 23 years is mediated by adolescent body mass index, and pubertal development, using the Birth-to-Twenty Plus cohort (South Africa).

Subjects/methods For 1036 participants, data on anthropometrics between birth and 23 years, maternal factors, and pubertal development (Tanner scale at 9-16 years) were collected. Stunting at 2 years (height-for-age $z$-score $<-2$ ), 5-18 years BMIfor-age trajectories, pubertal development trajectories, and DXA-derived fat mass (FM) and fat free mass (FFM) at 23 years were determined. Data were analysed using hierarchical regressions and structural equation models.

Results Stunting was directly associated with slower pubertal development and with shorter adult stature, but was not associated with adolescent BMI trajectories, adult FM or FFM. However, stunting was indirectly associated with adult FM and FFM through the direct associations between slower pubertal development and lower FM and between shorter height and lower FFM. BMI trajectories were independently associated with FM and FFM.

Conclusions Being stunted in this population predicted adult body composition through slower pubertal development and shorter adult stature.
\end{abstract}

These authors contributed equally: Glory Chidumwa, Rihlat SaidMohamed

Supplementary information The online version of this article (https:// doi.org/10.1038/s41430-020-00716-1) contains supplementary material, which is available to authorized users.

Rihlat Said-Mohamed

rs2087@cam.ac.uk

1 SAMRC/Wits Developmental Pathways for Health Research Unit, Department of Paediatrics and Child Health, School of Clinical Medicine, Faculty of Health Sciences, University of the Witwatersrand, 7 York Rd, Parktown, Johannesburg 2193, South Africa

2 Department of Archaeology, Faculty of Human, Social and Political Science, School of Humanities and Social Sciences, University of Cambridge, Cambridge, UK

3 Division of Epidemiology and Biostatistics, School of Public Health, University of the Witwatersrand, Johannesburg, South Africa

4 Institute of Developmental Sciences, University of Southampton, Southampton, UK

\section{Introduction}

In low- and middle-income countries (LMICs), obesity has become a critical determinant of morbidity and mortality due to its association with higher risks of cardiovascular and metabolic diseases [1]. The rapid nutrition transition, which intersects with persistent undernutrition in LMICs poses a double burden of malnutrition [2]. In 2016, $44 \%$ of overweight children under 5 years of age and $66 \%$ of stunted children under 5 years of age were reported to be living in LMICs [3]. While there has been a decrease in the prevalence of stunting globally, the trends in Africa are worrisome. It is the only region that has experienced an increase in the prevalence of stunting in children under 5 years of age while the number of overweight children of the same age has increased by nearly $50 \%$ since the year 2000 , and $12 \%$ of adults are also obese [3, 4].

A life-course approach may contribute to a better understanding of the antecedents of obesity. Physical growth during the developmental period from conception through to early childhood may be a critical determinant of 
adult body composition and obesity risk [5]. In LMICs, both rapid linear growth and weight gain between birth and 2 years of age have been shown to contribute to greater adult lean mass and height in comparison to adult fat mass (FM), while from 2 years of age onwards evidence is consistent with observations in high income countries, which shows that rapid weight gain becomes a risk factor for overweight/obesity, and greater FM [6-11]. During the adolescent transition, pubertal timing (onset) and progression (tempo, speed of pubertal development) may also play an important role in influencing body composition and obesity risk in adulthood [12,13]. Early and late onset of menarche and faster progression through puberty have been associated with higher body mass index (BMI) and adiposity levels in adulthood [12]. Findings from LMICs have consistently shown that greater height and weight gain during early childhood predict an earlier onset of puberty and a faster tempo of pubertal development [14, 15]. In addition, both greater growth rate during childhood and faster pubertal development during adolescence were found to be risk factors for overweight and obesity in young adulthood [6, 10]. Findings from LMICs with regards to whether stunting plays a role are less clear. Childhood stunting has been associated with late onset pubertal development [16, 17]. However, stunting in children has not been consistently associated with the risk of overweight or obesity in childhood and adolescence [18-22].

South Africa is experiencing a double burden of malnutrition; it has one of the highest prevalence of obesity in adults and children in the sub-Saharan region, while $26 \%$ of children under 3 years of age are classified as stunted [23]. The South African Birth-to-Twenty Plus prospective cohort study (BT20+) is the largest and longest running (1990-present) birth cohort in sub-Saharan Africa, and offers a unique opportunity to explore the associations between undernutrition in childhood, pubertal development, and risks of obesity in adulthood [24]. In previous analyses of data from the BT20+ study [22, 25], stunting at 2 years of age was not associated with BMI nor with overweight and obesity risks between 4 and 24 years age. However, using imaging data (DXA) of the BT20+ participants, results consistently showed that stunting at 2 years of age was associated with lower fat free mass (FFM) at 7-9 years, 10 years and 23 years of age $[8,25,26]$. In addition, in the same cohort, males' and females' pre-pubertal weight and height as well as the timing of the onset of pubertal development were associated with BMI in young adulthood suggesting that pubertal development may mediate the associations between growth in childhood and body composition in young adulthood [13]. Using hierarchical regressions and structural equation modelling (SEM), this study aimed to determine whether changes in BMI from childhood through to late adolescence, and/or the tempo of pubertal development, mediate the association between stunting, and height and body composition (FM and FFM) in young adulthood in the BT20+ cohort.

\section{Methods}

\section{Study design and setting}

The Birth-to-Twenty Plus prospective cohort was set up to observe growth, development and health in an urban cohort following the democratic transition in the Republic of South Africa. Inclusion and exclusion criteria for the BT20+ study have been described elsewhere [24]. Between 23 April and 8 June 1990, this birth cohort study included 3273 mothers and their singleton newborns born in Soweto (Johannesburg, South Africa) who were to remain in the area until the child turned 6 months of age. Since their birth, information on growth, diet, physiological indicators, and health have been collected amongst other characteristics at each of the 23 data collection waves, and the current wave at age 28 years has just been completed. The Human Research Ethics Committee of University of the Witwatersrand (South Africa) granted ethical clearance for this study (M111182) and the study was conducted in line with the Principles of the Declaration of Helsinki for research involving human subjects. Participants and their caregivers provided written informed assent (where appropriate) and consent.

\section{Anthropometric indices and trajectories}

Anthropometric data were collected regularly from birth to 23 years. Weight and supine length up to age 2 years and standing height after age 2 years, were collected by trained research assistants using standard techniques [27]. For each participant, height to the nearest $0.1 \mathrm{~cm}$ was measured using a wall-mounted stadiometer (Holtain, UK) and weight to the nearest $0.1 \mathrm{~kg}$ was measured using a digital scale with participants in light clothes and without shoes.

\section{Stunting at age 2 years}

Height-for-age $z$-score (HAZ) at age 2 years was derived from the World Health Organization sex-specific growth standards [28] and stunting was defined as $\mathrm{HAZ}<-2$.

\section{BMI trajectories between 5 years and 18 years}

BMI trajectory groups from five years to 18 years have been previously determined using latent class growth mixture modelling (Supplementary Fig. S1) [29]. The characterisation of BMI trajectories permitted the identification of 
sex-specific adiposity patterns and tracking from early childhood to late adolescence. Females could belong to one of the following four BMI trajectory groups: "(1) normal weight (2), late onset overweight (3), early onset obesity to overweight and (4) early onset obesity to morbid obese". Male trajectory groups were identified and classified as: "(1) normal weight (2), early onset overweight to normal and (3) early onset overweight to obese".

\section{Pubertal development trajectories}

The Tanner sexual maturation scale was used to determine the stage of pubertal development from 9 to 17 years. Sexspecific pubertal development trajectory classes have been determined previously using latent class growth analyses [14]. Four classes of breast development were identified for girls and four classes of genital development were identified for boys (Supplementary Fig. S2). For boys' and girls' trajectories, participants in trajectory class 1 had the slowest pubertal development, while those in the highest trajectory class were characterised by the fastest pubertal development.

\section{Fat mass and fat free mass at age 23 years}

Participants' whole body composition was measured according to standard procedures with dual-energy $\mathrm{x}$-ray absorptiometry (DXA; Hologic QDR 4500A, Bedford, USA) by a trained technician. A daily calibration of the DXA machine was performed using a phantom spine; coefficients of variation for total FM and FFM were $<2 \%$ and $1 \%$, respectively. Each scan was analysed excluding the head with the DXA software version 4.0.2 (Hologic Inc., Bedford, USA) to derive whole body FM and FFM.

\section{Maternal factors}

Interviewer-administered questionnaires were completed with the mothers or caregivers of the BT20+ participants when participants were 6 months, 1 year and 2 years of age. Information on maternal education, parity, and age was collected at each occasion. A household socio-economic index was calculated by summing all the physical/economic assets owned in the household [30].

\section{Study sample}

Participants included in this study were all BT20+ participants at 23 years of age who had not been pregnant between 17 and 23 years of age, and had the following data: anthropometry at 2 years of age, pubertal trajectories from 9 to 17 years, BMI trajectories between 5 years and 18 years, and DXA-derived body FM and FFM at 23 years of age.

\section{Statistical analyses}

Stata software 15.1 (StataCorp, College Station, TX: Stata Corporation) was used for all analyses. Normality was tested using the Shapiro-Wilk test, and study characteristics were compared between males and females using the Wilcoxon sum-rank and chi-squared tests. In males and females, bivariate analyses were performed to assess the associations between maternal factors, stunting at age 2 years, and pubertal development and body composition, using linear regression and multinomial logit models. In addition, hierarchical regressions were performed to assess the associations between stunting and adult FM and FFM, and to assess the potential contributions of pubertal development in the adolescent period and adult height. Model 1 was unadjusted, in Model 2 adolescent pubertal trajectories was controlled for, and in Model 3 adolescent pubertal trajectories and adult height were controlled for. Then, SEM analyses were used to determine whether pubertal development and adult height mediated the association between stunting at 2 years and adult body composition (FM and FFM). Multivariable analyses and SEM were based and guided by an a priori conceptual model (Fig. 1). Bold lines represent statistically significant paths while dotted lines represent paths that were not statistically significant. We conducted analyses separately for males and females.

\section{Results}

\section{Descriptive statistics}

A total of 1036 participants were included in the analyses (Table 1). At age 2 years, $27.4 \%$ of males and $18.4 \%$ of females were stunted (Table 1). Through 9-16 years of age, $25 \%$ of females were in the fastest pubertal development trajectory compared to $11 \%$ of the males who were in the fastest trajectory. The majority of participants (94\% of males and $83 \%$ of females) followed the "normal weight" BMI trajectory. At age 23 years, males and females differed in their stature and body composition; females were shorter by $11.9 \mathrm{~cm}(p<0.001)$, had a higher BMI $(24.3 \mathrm{vs.} 20.8 \mathrm{~kg}$. $\left.\mathrm{m}^{2}, p<0.001\right)$, had twice as much FM as males $(p<0.001)$, and $25 \%$ less FFM $(p<0.001)$.

\section{Bivariate analyses}

In bivariate analyses (Table 2), stunting at 2 years was not associated with adult FM or FFM in males or females. In males, stunting was associated with a lower relative risk of being in faster pubertal trajectories 2, 3 and 4, and a lower adult height by $6.1 \mathrm{~cm}(p<0.001)$. In females, stunting was associated with a lower relative risk of being in the faster 
a) Fat mass in males

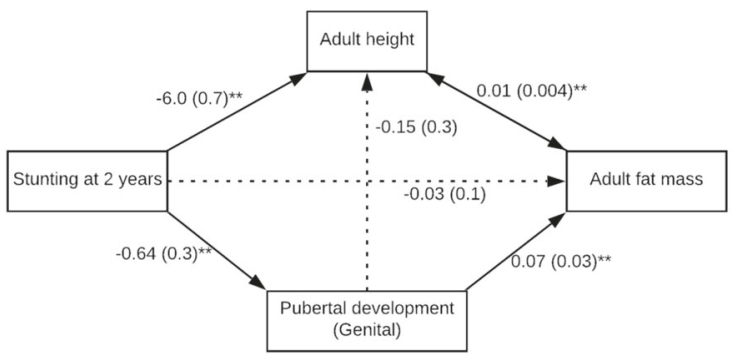

c) Fat free mass in males

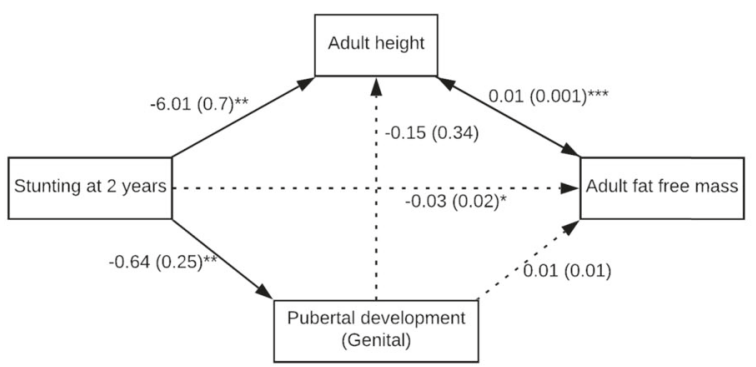

Fig. 1 Structural equation models for the association between stunting and fat mass and fat free mass in male and female participants of the Birth-to-twenty Plus cohort study. The solid lines represent significant direct effects and the dashed line is not a significant direct effect. All values are coefficients with standard errors in parenthesis. Significance levels: $* p$ value $<0.1 ; * * p$ value $<0.05$;

pubertal trajectories 3 and 4, and with lower adult height by $4.5 \mathrm{~cm}(p<0.001)$. Stunting was not associated with BMI trajectories in males, and in females it was associated with a higher relative risk to have a later onset overweight trajectory 1. In both sexes BMI trajectories had stronger associations with FM and FFM than pubertal trajectories (Table 3). Both pubertal and BMI trajectories had stronger associations with FM compared to FFM (Table 3).

\section{Hierarchical regression}

Stunting at 2 years was not associated with adult FM in males or females (Table 4). In males, pubertal development was associated with FM only when height was adjusted for (Model 3) and an increase in adult height was significantly associated with greater FM. In females, participants within the faster pubertal development trajectory class had significantly higher FM compared to their counterparts within the slowest pubertal development trajectory class. Contrasting with males, females' adult height was not associated with FM.

Concerning FFM (Table 5), stunting was associated with lower FFM in males and females at 23 years before adjusting for adult height. An increase in adult height was then significantly associated with greater adult FFM in both sex. For both sexes, in model 1 and 2 stunting was b) Fat mass in females

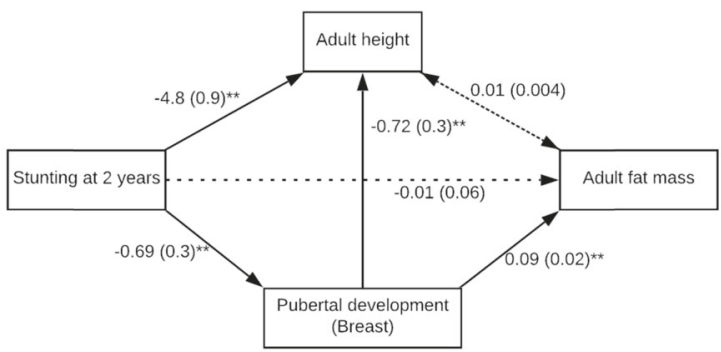

d) Fat free mass in females

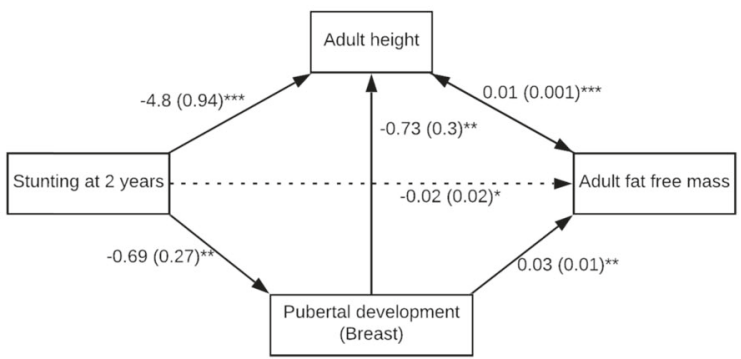

*** $p$ value $<0.001$. The model fit statistics were: the Root Mean Square Error of Approximation for (a): 0.022 (0.019-0.024), (b): 0.027 (0.023-0.32), (c): 0.42 (0.39-0.44), (d): 0.016 (0.009-0.021); the Comparative Fit Index for (a): 0.781, (b): 0.920, (c): 0.844, (d): 0.764; the Tucker-Lewis Index for (a): 0.778, (b): 0.905, (c): 0.800, (d): 0.759 .

associated with a reduced FFM of $\sim 90 \mathrm{~g}$. In model 3, adjusting for height, this association was no longer significant, but an increase by $1 \mathrm{~cm}$ in adult height was associated with greater FFM by $10 \mathrm{~g}$. These results suggest that adult height may mediate the association between stunting at 2 years of age and FFM. In males, while the addition of pubertal development in Model 2 did not change the variance explained by the model, the addition of adult height in Model 3 explained an additional $16 \%$ of the variance in adult FFM. In females, the addition of pubertal development in Model 2 explained an additional 3\% of the variance in adult FFM, while the addition of adult height in Model 3 explained an additional $20 \%$ of the variance in adult FFM.

\section{Structural equation modelling}

In both males and females, stunting at 2 years had no direct effect on FM or FFM. In males, stunting had statistically significant indirect (through adult height and through pubertal trajectory) and total effect on FM (Fig. 1a). These results were similar in females; however, stunting had an indirect effect on FM only through pubertal trajectory (Fig. 1b).

For FFM, the total effect of stunting in males and females was statistically significant. Furthermore, for both 
Table 1 Developmental characteristics of the Birth-to-twenty Plus cohort participants through age 23 years and maternal characteristics.

\begin{tabular}{|c|c|c|c|c|}
\hline Variables & All $(N)$ & Males & Females & $p$ values \\
\hline \multicolumn{5}{|c|}{ BT20+ characteristics } \\
\hline \multicolumn{5}{|c|}{ Childhood through late adolescence } \\
\hline \multicolumn{5}{|c|}{$\begin{array}{l}\text { Stunting at age } 2 \\
\text { years }^{\mathrm{a}}\end{array}$} \\
\hline No & 458 & $209(72.6)$ & $249(81.6)$ & 0.008 \\
\hline Yes & 135 & $79(27.4)$ & $56(18.4)$ & \\
\hline \multicolumn{5}{|l|}{$\begin{array}{l}\text { Pubertal } \\
\text { development } \\
\text { trajectories }\end{array}$} \\
\hline 1 (slowest) & 222 & $126(24.3)$ & $96(18.8)$ & N/A \\
\hline 2 & 331 & $197(38.0)$ & $134(26.3)$ & \\
\hline 3 & 289 & $136(26.3)$ & $153(30.0)$ & \\
\hline 4 (fastest) & 186 & 59 (11.4) & $127(24.9)$ & \\
\hline \multicolumn{5}{|l|}{$\begin{array}{l}\text { BMI trajectories } \\
(N=810)\end{array}$} \\
\hline 0 & 804 & $436(94.0)$ & $368(82.5)$ & N/A \\
\hline 1 & 68 & $23(5.0)$ & $45(10.1)$ & \\
\hline 2 & 19 & $5(1.1)$ & $14(3.1)$ & \\
\hline 3 & 19 & N/A & $19(4.3)$ & \\
\hline \multicolumn{5}{|l|}{ At age 23 years } \\
\hline Age (years) ${ }^{c}$ & 996 & $23.3(22.5 ; 23.5)$ & $23.2(22.6 ; 23.5)$ & 0.57 \\
\hline Height $(\mathrm{cm})^{\mathrm{c}}$ & 997 & $\begin{array}{l}171.8 \\
(167.5 ; 175.7)\end{array}$ & $\begin{array}{l}159.9 \\
(155.2 ; 164.0)\end{array}$ & $<0.001$ \\
\hline Weight $(\mathrm{kg})^{\mathrm{c}}$ & 989 & $61.4(55.8 ; 69.9)$ & $61.8(53.6 ; 71.6)$ & 0.83 \\
\hline $\begin{array}{l}\text { Body mass } \\
\text { index. }\left(\mathrm{kg} / \mathrm{m}^{2}\right)^{\mathrm{c}}\end{array}$ & 989 & $20.8(19.2 ; 23.3)$ & $\begin{array}{l}24.32 \\
(21.0 ; 28.5)\end{array}$ & $<0.001$ \\
\hline Fat Mass $(\mathrm{kg})^{\mathrm{c}}$ & 990 & $11.0(8.7 ; 15.1)$ & $22.8(17.4 ; 30.4)$ & $<0.001$ \\
\hline $\begin{array}{l}\text { Fat free mass } \\
(\mathrm{kg})^{\mathrm{c}}\end{array}$ & 1036 & $43.8(39.9 ; 48.0)$ & $32.6(30.0 ; 36.6)$ & $<0.001$ \\
\hline \multicolumn{5}{|c|}{ Maternal characteristics } \\
\hline \multicolumn{5}{|c|}{ Maternal Parity ${ }^{\mathrm{a}}$} \\
\hline One child & 382 & $195(37.3)$ & $187(36.5)$ & 0.78 \\
\hline $\begin{array}{l}\text { More than one } \\
\text { child }\end{array}$ & 654 & $328(62.7)$ & $326(63.6)$ & \\
\hline \multicolumn{5}{|l|}{$\begin{array}{l}\text { Maternal } \\
\text { Education }^{\mathrm{a}}\end{array}$} \\
\hline Primary & 125 & 71 (13.6) & $54(10.5)$ & 0.02 \\
\hline Secondary & 437 & $234(44.7)$ & $203(39.6)$ & \\
\hline $\begin{array}{l}\text { University/ } \\
\text { college }\end{array}$ & 474 & $218(41.7)$ & $256(49.9)$ & \\
\hline $\begin{array}{l}\text { Maternal age at } \\
\text { birth (years) }\end{array}$ & 1035 & $25(21 ; 30)$ & $25(21 ; 30)$ & 0.98 \\
\hline
\end{tabular}

N/A not applicable.

${ }^{a}$ Values are $\mathrm{N}$ (Frequencies).

bMales BMI trajectories: (0) normal weight, (1) early onset overweight to normal and (2) early onset overweight to obese; Females BMI trajectories: (0) normal weight (1), late onset overweight (2), early onset obesity to overweight and (3) early onset obesity to morbid obese.

${ }^{\mathrm{c}}$ Values are Medians (Inter-Quartile range (IQR)).

sexes, being stunted was indirectly associated with FFM through adult height. Stunting at 2 years was indirectly associated with FFM through pubertal trajectory in females but not males (Fig. 1c, d).
Table 2 Bivariate associations between stunting at age 2 years and pubertal development, adult height and body composition in male and female participants of the Birth-to-twenty Plus cohort study $(N=$ 1036).

\begin{tabular}{|c|c|c|}
\hline Variables & $\begin{array}{l}\text { Males } \\
\text { RRR }(95 \% \mathrm{CI})\end{array}$ & $\begin{array}{l}\text { Females } \\
\text { RRR }(95 \% \mathrm{CI})\end{array}$ \\
\hline \multicolumn{3}{|c|}{ Pubertal development trajectories } \\
\hline 1 vs. 2 & $0.48(0.24 ; 0.95)^{* *}$ & $1.18(0.55 ; 2.54)$ \\
\hline 1 vs. 3 & $0.45(0.22 ; 0.92)^{* *}$ & $0.41(0.17 ; 1.00)^{*}$ \\
\hline 1 vs. 4 & $0.31(0.12 ; 0.80)^{* *}$ & $0.45(0.17 ; 1.15)^{*}$ \\
\hline \multicolumn{3}{|l|}{ BMI trajectories } \\
\hline 0 vs. 1 & $1.02(0.26 ; 3.95)$ & $3.58(1.58 ; 8.15)^{* *}$ \\
\hline 0 vs. 2 & $1.35(0.12 ; 15.21)$ & - \\
\hline \multirow[t]{2}{*}{0 vs. 3} & & $0.98(0.21 ; 4.62)$ \\
\hline & Coefficient $(95 \% \mathrm{CI})$ & Coefficient $(95 \% \mathrm{CI})$ \\
\hline Height at 23 years & $-6.1(0.73)^{* * *}$ & $-4.5(0.93) * * *$ \\
\hline Fat mass at 23 years & $-0.04(0.06)$ & $-0.03(0.06)$ \\
\hline $\begin{array}{l}\text { Fat free mass at } \\
23 \text { years }\end{array}$ & $-0.33(0.25)$ & $-0.37(0.28)$ \\
\hline
\end{tabular}

Analyses are: multinomial logit models (risk ratios and 95\% confidence intervals) for pubertal development and BMI trajectories; linear regression models (coefficient are simple linear regression coefficients; standard errors in parenthesis) for adult height, fat mass and fat free mass. Significance levels: $* p<0.05 ; * * p<0.01 * * * p<$ 0.001 ; - shows perfect prediction and hence no estimates. All estimates are for stunted participants, with non-stunted participants as the reference. Males BMI trajectories: (0) normal weight, (1) early onset overweight to normal and (2) early onset overweight to obese; Females BMI trajectories: (0) normal weight, (1) late onset overweight (2), early onset obesity to overweight and (3) early onset obesity to morbid obese.

\section{Discussion}

We demonstrated that the association between stunting at 2 years of age and adult body composition was moderated by attained adult height and by the tempo of pubertal development. In this population, we show that males and females who were previously stunted were more likely to have a slower pubertal development and a shorter adult height. In stunted males, slower pubertal development and shorter adult height predicted lesser adult FM, while lower FFM was only predicted by shorter adult height. In females, slower pubertal development predicted lower FM, while slower pubertal development and shorter adult stature predicted lower FFM.

The thrifty phenotype hypothesis suggests that children with impaired growth during intrauterine and infancy periods are at greater risk of developing type 2 diabetes and the metabolic syndrome [31]. These disease may be induced by changes in glucose and insulin metabolisms as well as physiological energy sparing mechanisms resulting from the 
Table 3 Bivariate associations between pubertal development trajectories, BMI trajectories and adult height, and adult body composition, in male and female participants of the Birth-to-twenty Plus cohort study.

\begin{tabular}{|c|c|c|c|c|}
\hline \multirow[t]{2}{*}{ Variables } & \multicolumn{2}{|c|}{ Males } & \multicolumn{2}{|c|}{ Females } \\
\hline & $N$ & Coefficient (SE) & $N$ & Coefficient (SE) \\
\hline
\end{tabular}

Fat mass

Pubertal development trajectories

$\begin{array}{lrlrl}1 \text { - Slowest } & 123 & \text { Reference } & 90 & \text { Reference } \\ 2 & 187 & 0.07(0.05) & 129 & 0.11(0.05)^{*} \\ 3 & 129 & 0.17(0.05)^{* *} & 144 & 0.08(0.05) \\ 4 \text { - Fastest } & 58 & 0.15(0.07)^{*} & 122 & 0.27(0.05)^{* *} \\ \begin{array}{l}\text { BMI } \\ \text { rajectories }\end{array} & & & & \\ 0 & 419 & \text { Reference } & 350 & \text { Reference } \\ 1 & 22 & 0.59(0.08)^{* *} & 44 & 0.28(0.06)^{* *} \\ 2 & 5 & 0.86(0.17)^{* *} & 13 & 0.28(0.10)^{* *} \\ 3 & & \text { N/A } & 18 & 0.64(0.09)^{* *} \\ \text { Height at } & 482 & 0.01(0.003)^{* *} & 470 & 0.01(0.003)\end{array}$

23 years

Fat free mass

Pubertal development trajectories

126 Reference

$2 \quad 197 \quad 0.02(0.02)$

$3 \quad 1360.03(0.02)^{*}$

4 - Fastest $\quad 590.04(0.02)$

BMI trajectories

$\begin{array}{rrl}0 & 436 & \text { Reference } \\ 1 & 23 & 0.07(0.03)^{*} \\ 2 & 5 & 0.24(0.06)^{* *} \\ 3 & & \text { N/A }\end{array}$

Height at

$5030.01(0.003)^{* *}$

23 years

All values are linear regression coefficients with standard errors in parentheses; Significance levels: $* * p<0.01$, $* p<0.05$. Males BMI trajectories: (0) normal weight, (1) early onset overweight to normal and (2) early onset overweight to obese; Females BMI trajectories: (0) normal weight, (1) late onset overweight (2), early onset obesity to overweight and (3) early onset obesity to morbid obese. exposure to undernutrition in early life [31]. Building on this hypothesis, it has been suggested that in response to early-life undernutrition, stunted children may be at a greater risk of storing fat, and of becoming overweight or obese adults, leading to the double burden of malnutrition at individual level [32, 33]. Impaired lipid metabolism [32], reduced resting energy expenditure [32, 34, 35], decreased physical activity levels [34, 35], and/or opportunistic overeating behaviour [36] are some of the mechanisms proposed by which stunted children may accumulate FM. Cross-sectional surveys have found contrasting results regarding the risk for stunted children to develop overweight and obesity during childhood or adolescence; either an increased risk or no association [18, 37, 38]. In a crosssectional sample of 10-15 year old adolescents in South Africa there was no association between stunting and overweight [18], while a study using data from a crosssectional national survey found that stunted children under the age of 6 years had a relative risk of $2.6(2.0-3.4)$ of being overweight [37]. Our results support and expand findings from longitudinal studies, which have consistently reported no direct association between stunting in early life and the risk of overweight or obesity during childhood or adolescence [21, 22, 25]. Indeed, using hierarchical regressions and then SEM, our study shows an indirect association between stunting during childhood and adult body composition. Our data suggests that previously stunted persons are more likely to become shorter adults $[39,40]$ who, in our population, are in turn characterised by lower FM and FFM in males, and lower FFM in females. Stunting has been associated with lower FM and FFM in childhood, adolescence and adulthood [25, 41, 42]. A shorter adult stature in previously stunted children may translate into lower bone and muscle mass, resulting in less FFM in comparison to their non-stunted counterparts [8, 34]. In cases of continued undernutrition, stunted

Table 4 Unadjusted and adjusted associations between stunting at 2 years and fat mass at 23 years in male and female participants of the Birth-totwenty Plus cohort study.

\begin{tabular}{|c|c|c|c|c|c|c|c|c|c|c|c|c|}
\hline \multirow[t]{2}{*}{ Variables } & \multicolumn{6}{|c|}{ Males } & \multicolumn{6}{|c|}{ Females } \\
\hline & $N$ & Model 1 & $N$ & Model 2 & $N$ & Model 3 & $N$ & Model 1 & $N$ & Model 2 & $N$ & Model 3 \\
\hline \multicolumn{13}{|l|}{ Stunting at 2 years } \\
\hline No & 198 & Reference & 197 & Reference & 188 & Reference & 238 & Reference & 238 & Reference & 230 & Reference \\
\hline Yes & 79 & $-0.10(0.06)$ & 77 & $-0.10(0.06)$ & 75 & $-0.03(0.07)$ & 54 & $-0.08(0.06)$ & 53 & $-0.04(0.06)$ & 50 & $-0.01(0.06)$ \\
\hline \multicolumn{13}{|c|}{ Pubertal development trajectories } \\
\hline 1 - Slowest & & & 59 & Reference & 57 & Reference & & & 55 & Reference & 54 & Reference \\
\hline 2 & & & 95 & $0.05(0.07)$ & 89 & $0.10(0.07)$ & & & 85 & $0.05(0.07)$ & 82 & $0.06(0.07)$ \\
\hline 3 & & & 80 & $0.11(0.08)$ & 78 & $0.13(0.07)$ & & & 84 & $0.09(0.07)$ & 80 & $0.10(0.07)$ \\
\hline 4 - Fastest & & & 40 & $0.15(0.09)$ & 39 & $0.22(0.09)^{*}$ & & & 67 & $0.28(0.07)^{* *}$ & 64 & $0.28(0.07)^{* *}$ \\
\hline Height at 23 years & & & & & 263 & $0.01(0.003)^{*}$ & & & & & 280 & $0.01(0.003)$ \\
\hline Observations & & 277 & & 274 & & 263 & & 292 & & 291 & & 280 \\
\hline R-squared & & 0.01 & & 0.03 & & 0.06 & & 0.01 & & 0.07 & & 0.07 \\
\hline
\end{tabular}

All values are linear regression coefficients with standard errors in parentheses; Significance levels: ${ }^{*} p<0.05 ; * * p<0.01$. 
Table 5 Unadjusted and adjusted associations between stunting at 2 years and fat free mass at 23 years in male and female participants of the Birthto-twenty Plus cohort study.

\begin{tabular}{|c|c|c|c|c|c|c|c|c|c|c|c|c|}
\hline \multirow[t]{2}{*}{ Variables } & \multicolumn{6}{|c|}{ Males } & \multicolumn{6}{|c|}{ Females } \\
\hline & $N$ & Model 1 & $N$ & Model 2 & $N$ & Model 3 & $N$ & Model 1 & $N$ & Model 2 & $N$ & Model 3 \\
\hline \multicolumn{13}{|l|}{ Stunting at 2 years } \\
\hline No & 209 & Reference & 208 & Reference & 199 & Reference & 249 & Reference & 249 & Reference & 240 & Reference \\
\hline Yes & 79 & $-0.09(0.02)^{* *}$ & 77 & $-0.09(0.02)^{* *}$ & 75 & $-0.03(0.02)$ & 56 & $-0.09(0.02)^{* *}$ & 55 & $-0.08(0.02)^{* *}$ & 52 & $-0.02(0.02)$ \\
\hline \multicolumn{13}{|c|}{ Pubertal development trajectories } \\
\hline 1 - Slowest & & & 61 & Reference & 59 & Reference & & & 60 & Reference & 59 & Reference \\
\hline 2 & & & 100 & $0.02(0.02)$ & 94 & $0.03(0.02)$ & & & 87 & $0.00(0.03)$ & 84 & $0.01(0.02)$ \\
\hline 3 & & & 84 & $0.01(0.02)$ & 82 & $0.01(0.02)$ & & & 90 & $0.00(0.02)$ & 85 & $0.03(0.02)$ \\
\hline 4 - Fastest & & & 40 & $0.03(0.03)$ & 39 & $0.05(0.03)^{*}$ & & & 67 & $0.07(0.03)^{* * *}$ & 64 & $0.09(0.02)^{* *}$ \\
\hline Height at 23 years & & & & & 274 & $0.01(0.003)^{* *}$ & & & & & 292 & $0.01(0.003)^{* *}$ \\
\hline Observations & & 288 & & 285 & & 274 & & 305 & & 304 & & 292 \\
\hline R-squared & & 0.09 & & 0.09 & & 0.25 & & 0.05 & & 0.08 & & 0.28 \\
\hline
\end{tabular}

All values are linear regression coefficients with standard errors in parentheses; Significance levels: $* p<0.05 ; * * p<0.01$.

children may preferentially use energy from protein stored in muscles with such catabolism also potentially resulting in reduced muscle mass [43]. Our results are consistent with large cohort studies, which have found that in LMICs rapid length and weight gain in the first 2 years of life predicted greater adult height and lean mass $[9,10,33]$. Concerning adiposity, stunting has been associated with greater central and visceral FM during adolescence and adulthood (as measured by DXA, ultrasound and other techniques) suggesting that stunting may have a stronger effect on body fat distribution rather than on whole body FM [44].

Previous studies in LMICs have found that stunting was associated with later onset of puberty $[16,17,45]$. Our data extends this by showing that stunting was associated with slower pubertal development and that, in turn, slower pubertal development predicted lower FM in adult males and females, and lower FFM only in females. Sex differences in these associations during the pubertal transition have also been reported in Brazil [46]. The adolescence transition is characterised by significant changes in body composition associated with pubertal development [47]. In this study, BMI trajectories through childhood and adolescence had the strongest associations with adult FM. Our results support this for both sexes, with transient (temporary periods of) overweight or obesity during adolescence independently conferring greater body FM and FFM in adulthood [6, 12, 13, 48]. During pubertal development, both males and females gain in adiposity, but this is more pronounced in females [47]. In males, a marked increase in muscle mass is expected [47]. In the present study, in both sexes, a faster pubertal development was associated with greater adult FM and FFM, with stronger associations between faster pubertal development and FM. This finding adds to our understanding of the respective associations between the onset of and the tempo of menarche and adiposity levels [12]. Observed differences between males and females may also be related to hormonal and behavioural changes during the adolescence transition [49, 50].

The strength of this study is in the longitudinal assessment of the role of adolescent BMI trajectories and pubertal development in the association between stunting with adult body composition. The results from the present study adds to previous finding from this cohort by showing that the effect of early childhood stunting on FFM is on the decrease in adult height and the slow-down of pubertal tempo $[8,22,25,26]$. However, this study is not without limitations; we have not investigated the association between stunting and FM distribution taking into account adolescent BMI and pubertal development; specific analyses will explore these particular associations using the combination of body composition data measured by DXA and ultrasound. While warranted, these analyses will need to be treated with caution as DXA accuracy is limited in determining adiposity in obese participants, with poorer precision for regional distribution, particularly FM percentage at the trunk in comparison to total body FM [51, 52]. In addition, we have not included other environmental factors such as dietary patterns, physical activity or socio-economic status that may affect body composition. The effects of such factors accumulate throughout the life-course and are embodied in the observed body composition in adulthood $[53,54]$.

In conclusion, in this study stunting is associated with lower FM and FFM in young adults, acting through shorter adult height and slower pubertal development. The combination of shorter stature and lesser lean mass in LMICs, such as South Africa, where the prevalence of obesity is dramatically increasing, may lay the foundation for higher risks for cardio-metabolic diseases later in life. This hypothesis will be explored in the next follow-up of the BT20+. Our finding support that linear growth, weight gain, and changes in body composition should be monitored 
from childhood through adolescence to adulthood. There is an urgent need for life-course interventions starting from foetal period to promote trajectories that lead to healthier adult body composition.

Acknowledgements Our gratitude goes to all the participants of the Birth-to-Twenty Plus cohort, their parents and relatives for contributing for 30 years to this study. The support of the DST-NRF Centre of Excellence in Human Development is hereby acknowledged. Opinions expressed and conclusions arrived at, are those of the authors and are not necessarily attributed to the Centre of Excellence in Human Development. The South African Medical Research Council funded this work.

Funding TC is supported by the Wellcome Trust Training Fellowship, grant number: $214205 / \mathrm{Z} / 18 / \mathrm{Z}$.

Author contributions All authors conceived and/or designed the work that led to the submission, revised the paper, approved the final version, agreed to be accountable for all aspects of the work. GC, RSM and SAN carried out the data analyses and generated figures, interpreted the data, did the literature search, and the writing of the paper. LHN, JK and AP carried out the data analyses and interpreted the data. FM, TC, LJW and LKM made a significant contribution in the interpretation of the results.

\section{Compliance with ethical standards}

Conflict of interest The authors declare that they have no conflict of interest.

Publisher's note Springer Nature remains neutral with regard to jurisdictional claims in published maps and institutional affiliations.

Open Access This article is licensed under a Creative Commons Attribution 4.0 International License, which permits use, sharing, adaptation, distribution and reproduction in any medium or format, as long as you give appropriate credit to the original author(s) and the source, provide a link to the Creative Commons license, and indicate if changes were made. The images or other third party material in this article are included in the article's Creative Commons license, unless indicated otherwise in a credit line to the material. If material is not included in the article's Creative Commons license and your intended use is not permitted by statutory regulation or exceeds the permitted use, you will need to obtain permission directly from the copyright holder. To view a copy of this license, visit http://creativecommons. org/licenses/by/4.0/.

\section{References}

1. Ford N, Patel S, Narayan K. Obesity in low- and middle-income countries: burden, drivers, and emerging challenges. Annu Rev Public Health. 2017;38:145-64.

2. Prentice A. The double burden of malnutrition in countries passing through the economic transition. Ann Nutr Metab. 2018;72 (Suppl. 3):47-54.

3. UNICEF, WHO, World Bank. Levels and trends in child Malnutrition. Key findings of the 2017 edition. UNICEF/WHO/World Bank Group Joint Child Malnutrition Estimates; UNICEF: New York, US, WHO: Geneva, Switzerland, World Bank: Washington DC, US, 2017. https://www.who.int/nutgrowthdb/estimates2016/en/.

4. FAO, IFAD, UNICEF, WFP, WHO. The state of food security and nutrition in the world 2018. Building climate resilience for food security and nutrition [Internet]. Rome; 2018. http://www. who.int/nutrition/publications/foodsecurity/state-food-securitynutrition-2018-en.pdf?ua $=1$.

5. Gluckman PD, Hanson MA, Buklijas T. A conceptual framework for the developmental origins of health and disease. J Dev Orig Health Dis. 2010;1:6-18.

6. Munthali RJ, Kagura J, Lombard Z, Norris SA. Early life growth predictors of childhood adiposity trajectories and future risk for obesity: birth to twenty cohort. Child Obes. 2017;13:384-91.

7. Zheng M, Lamb K, Grimes C, Laws R, Bolton K, Ong K, et al. Rapid weight gain during infancy and subsequent adiposity: a systematic review and meta-analysis of evidence. Obes Rev. 2018;19:321-32.

8. Prioreschi A, Munthali R, Kagura J, Said-Mohamed R, De Lucia Rolfe E, Micklesfield L, et al. The associations between adult body composition and abdominal adiposity outcomes, and relative weight gain and linear growth from birth to age 22 in the Birth to Twenty Plus cohort, South Africa. PLoS ONE 2018;13:e0190483.

9. Kuzawa CW, Hallal PC, Adair L, Santosh K, Fall CHD, Lee N, et al. Birth weight, postnatal weight gain and adult body composition in five low and middle income countries. 2013;24(1):5-13.

10. Adair LS, Fall CHD, Osmond C, Stein AD, Martorell R, RamirezZea $\mathrm{M}$, et al. Associations of linear growth and relative weight gain during early life with adult health and human capital in countries of low and middle income: findings from five birth cohort studies. Lancet 2013;382:525-34.

11. Araújo de França G, De Lucia Rolfe E, Horta B, Gigante D, Yudkin J, Ong K, et al. Associations of birth weight, linear growth and relative weight gain throughout life with abdominal fat depots in adulthood: the 1982 Pelotas (Brazil) birth cohort study. Int J Obes. 2015;40:14-21.

12. Prentice P, Viner R. Pubertal timing and adult obesity and cardiometabolic risk in women and men: a systematic review and meta-analysis. Int J Obes. (Lond). 2013;37:1036-43.

13. Stein A, Lundeen E, Martorell R, Suchdev P, Mehta N, Richter L, et al. Pubertal development and prepubertal height and weight jointly predict young adult height and body mass index in a prospective study in South Africa. J Nutr. 2016;146:1394-401.

14. Lundeen E, Norris S, Martorell R, Suchdev P, Mehta N, Richter L, et al. Early life growth predicts pubertal development in South African adolescents. J Nutr. 2016;146:622-9.

15. German A, Shmoish M, Hochberg Z. Predicting pubertal development by infantile and childhood height, BMI, and adiposity rebound. Pediatr Res. 2015;78:445-50.

16. Leenstra T, Petersen L, Kariuki S, Oloo A, Kager P, Ter Kuile F. Prevalence and severity of malnutrition and age at menarche; cross-sectional studies in adolescent schoolgirls in western Kenya. Eur J Clin Nutr. 2005;59:41-8.

17. Bosch A, Willekens F, Baqui A, Van Ginneken J, Hutter I. Association between age at menarche and early-life nutritional status in rural Bangladesh. J Biosoc Sci. 2008;40:223-37.

18. Mukuddem-Petersen J, Kruger HS. Association between stunting and overweight among 10-15-y-old children in the North West Province of South Africa: the THUSA BANA Study. Int J Obes. 2004;28:842-51.

19. Fernald L, Neufeld L. Overweight with concurrent stunting in very young children from rural Mexico: prevalence and associated factors. Eur J Clin Nutr. 2007;61:623-32.

20. Cameron N, Wright M, Griffiths P, Norris S, Pettifor J. Stunting at 2 Years in Relation to Body Composition at 9 Years in African Urban Children. Obes Res. 2005;13:131-6.

21. Timæus IM. Stunting and obesity in childhood: a reassessment using longitudinal data from South Africa. Int $\mathrm{J}$ Epidemiol. 2012;41:764-72.

22. Hanson S, Munthali R, Lundeen E, Richter L, Norris S, Stein A. Stunting at 24 months is not related to incidence of overweight 
through young adulthood in an urban South African birth cohort. J Nutr. 2018;148:967-73.

23. Shisana O, Labadarios D, Rehle T, Simbayi L, Zuma K, Dhansay A, et al. The South African National Health and Nutrition Examination Survey: SANHANES-1 [Internet]. 2013 [cited 2014 Apr 10]. 423 p. http://scholar.google.com/scholar?hl=en\&btnG= Search\&q=intitle:South + African + National + Health + and + Nutrition+Examination + Survey +(SANHANES-1)\#0

24. Richter L, Norris S, Pettifor J, Yach D, Cameron N. Cohort profile: Mandela's children: the 1990 Birth to Twenty study in South Africa. Int J Epidemiol. 2007;36:504-11.

25. Cameron N, Wright M, Griffiths P, Norris S, Pettifor J. Stunting at 2 years in relation to body composition at 9 years in African urban children. Obes Res. 2005;13:131-6.

26. Kagura J, Feeley A, Micklesfield L, Pettifor J, Norris S. Association between infant nutrition and anthropometry, and prepubertal body composition in urban South African children. J Dev Orig Health Dis. 2012;3:415-23.

27. Lohman T, Roche A, Martorell R. Anthropometric standardization reference manual. In: Lohman T, Roche A, Martorell R, editors. Champaign, IL: Human Kinetics Publishers; 1988. p. 177.

28. WHO Multicentre Growth Reference Study Group. WHO Child Growth Standards based on length/height, weight and age. Acta Paediatr (Oslo, Norw 1992) Suppl. 2006;450:76-85.

29. Munthali RJ, Kagura J, Lombard Z, Norris SA. Childhood adiposity trajectories are associated with late adolescent blood pressure: birth to twenty cohort. BMC Public Health. 2016;16:665.

30. Pradeilles R, Griffiths PL, Norris SA, Feeley AB, Rousham EK. Socio-economic influences on anthropometric status in urban South African adolescents: sex differences in the Birth to Twenty Plus cohort. Public Health Nutr. 2015;18:2998-3012.

31. Hales CN, Barker DJP. The thrifty phenotype hypothesis: type 2 diabetes. Br Med Bull. 2001;60:5-20.

32. Hoffman D, Sawaya A, Verreschi I, Tucker K, Roberts S. Why are nutritionally stunted children at increased risk of obesity? Studies of metabolic rate and fat oxidation in shantytown children from São Paulo, Brazil. Am J Clin Nutr. 2000;72:702-7.

33. Wells J, Sawaya A, Wibaek R, Mwangome M, Poullas M, Yajnik $\mathrm{C}$, et al. The double burden of malnutrition: aetiological pathways and consequences for health. Lancet 2020;395:75-88.

34. Said-Mohamed R, Bernard JY, Ndzana AC, Pasquet P. Is overweight in stunted preschool children in Cameroon related to reductions in fat oxidation, resting energy expenditure and physical activity? PLoS ONE. 2012;7(6):e39007.

35. Wilson H, Dickinson F, Hoffman D, Griffiths P, Bogin B, VarelaSilva M. Fat free mass explains the relationship between stunting and energy expenditure in urban Mexican Maya children. Ann Hum Biol. 2012;39:432-9.

36. Hoffman D, Roberts S, Verreschi I, Martins P, de Nascimento C, Tucker K, et al. Regulation of energy intake may be impaired in nutritionally stunted children from the Shantytowns of Sa $\sim$ Paulo, Brazil. J Nutr. 2000;130:2265-70.

37. Popkin B, Richards M, Montiero C. Stunting is associated with overweight in children of four nations that are undergoing the nutrition transition. J Nutr. 1996;126:3009-16.

38. Symington E, Gericke G, Nel J, Labadarios D. The relationship between stunting and overweight among children from South Africa: Secondary analysis of the National Food Consumption Survey - Fortification Baseline I. South Afr Med J. 2016;106:65-9.
39. Coly A, Milet J, Diallo A, Ndiaye T, Bénéfice E, Simondon F, et al. Preschool stunting, adolescent migration, catch-up growth, and adult height in young senegalese men and women of rural origin. J Nutr. 2006;136:2412-20.

40. Stein AD, Wang M, Martorell R, Norris SA, Adair LS, Bas I, et al. Growth patterns in early childhood and final attained stature: data from five birth cohorts from low-and middle-income countries. Am J Hum Biol. 2010;22:353-9.

41. Tanner S, Leonard WR, Reyes-garc V. The consequences of linear growth stunting: influence on body composition among youth in the Bolivian Amazon. 2014;102:92-102.

42. Li H, Stein A, Barnhart H, Ramakrishnan U, Martorell R. Associations between prenatal and postnatal growth and adult body size and composition. Am J Clin Nutr. 2003;77: 1498-505.

43. Shetty P. Adaptation to low energy intakes: the responses and limits to low intakes in infants, children and adults. Eur J Clin Nutr. 1999;53(Suppl 1):S14-33.

44. Hoffman D, Martins P, Robert S, Sawaya A. Body fat distribution in stunted compared with normal-height children from the shantytowns of São Paulo, Brazil. Nutrition 2007;23:640-6.

45. Khan A, Schroeder D, Martorell R, Haas J, Rivera J. Early childhood determinants of age at menarche in rural guatemala. Am J Hum Biol. 1996;8:717-23.

46. Martins P, Hoffman D, Fernandes M, Nascimento C, Roberts S, Sesso R, et al. Stunted children gain less lean body mass and more fat mass than their non-stunted counterparts: a prospective study. Br J Nutr. 2004;92:819-25.

47. Siervogel R, Demerath E, Schuber C, Remsberg K, Chumlea W, Sun S, et al. Puberty and body composition. Horm Res. 2003;60 (Suppl. 1):36-45.

48. Said-Mohamed R, Prioreschi A, Nyati L, van Heerden A, Munthali R, Kahn K, et al. Rural-urban variations in age at menarche, adult height, leg-length and abdominal adiposity in black South African women in transitioning South Africa. Ann Hum Biol. 2018;45:123-32.

49. Mongraw-Chaffin ML, Anderson C, Allison M, Ouyang P, Szklo M, Vaidya D, et al. Association between sex hormones and adiposity: qualitative differences in women and men in the multiethnic study of atherosclerosis. J Clin Endocrinol Metab. 2015; 100:E596-600.

50. Peer N, Bradshaw D, Laubscher R, Steyn N, Steyn K. Urban-rural and gender differences in tobacco and alcohol use, diet and physical activity among young black South Africans between 1998 and 2003. Glob Heatlth Action 2013;6:19216.

51. Wells J, Haroun D, Williams J, Wilson C, Darch T, Viner R, et al. Evaluation of DXA against the four-component model of body composition in obese children and adolescents aged 5-21 years. Int J Obes. 2010;34:649-55.

52. Bazzocchi A, Ponti F, Albisinni U, Battista G, Guglielmi G. DXA: technical aspects and application. Eur J Radio. 2016;85: 1481-92.

53. Bann D, Cooper R, AK W, Adams J, Kuh D. NSHD scientific and data collection team. Socioeconomic position across life and body composition in early old age: findings from a British birth cohort study. J Epidemiol Community Heal. 2014;68:516-23.

54. Emmett P, Jones L. Diet, growth, and obesity development throughout childhood in the Avon Longitudinal Study of Parents and Children. Nutr Rev. 2015;73(Supll. 3):175-206. 